\title{
$S_{R} Q_{E} L_{V} E T R T_{T} A_{A} S$
}

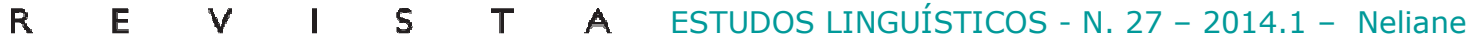
Raquel M. Aquino e Carine Haupt

\section{O livro didático no ensino de língua estrangeira: atividades de pronúncia}

\author{
Neliane Raquel Macedo Aquino ${ }^{1}$ \\ Universidade Federal do Tocantins \\ Carine Haupt ${ }^{2}$ \\ Universidade Federal do Tocantins
}

Resumo: As teorias de aquisição de linguagem nos permitem refletir sobre a prática de sala de aula que temos hoje. Ao pensar nessa relação, também é necessário que o material disponível aos professores seja analisado. Nessa perspectiva, propõe-se neste artigo, a partir de uma breve revisão teórica sobre o interacionismo e a abordagem comunicativa, uma reflexão das propostas de atividades de um livro didático em relação às atividades específicas de pronúncia em sala de aula. Tomamos como recorte para essa análise o livro Freeway (2010) - ensino de inglês como língua estrangeira (LE) - por ser o único escolhido pelo MEC, e adotado por escolas públicas, que contém atividades que trabalham a pronúncia baseadas em conhecimentos fonético-fonológicos. A relevância de se discutir esta questão reside na importância de o aluno perceber as diferenças dos sistemas sonoros da língua materna e da língua alvo no processo de aquisição desta. Observamos que as atividades do livro são pertinentes, mas não condizem com uma abordagem comunicativa, conforme sugerem os autores da obra. Embora ainda haja certa distância entre o que propõe o autor e o que termina por ser realizado na prática, essas atividades de treino de pronúncia melhoram o desempenho e podem, consequentemente, auxiliar em uma comunicação efetiva.

Palavras-chave: Língua Inglesa; Livro didático; Pronúncia; Interacionismo; Abordagem Comunicativa.

\section{Introdução}

“Ensinar é, no máximo, esperar que o melhor aconteça”, já disse Prahbu (1992, p. 79). E, para que possamos, pelo menos, ter essa esperança é preciso pensar sobre a prática. A teoria, então, ilumina o caminho da reflexão. Por isso, teoria e prática não devem ser considerados como percursos diferentes, mas como um conjunto que explica, desenvolve as possibilidades de conhecimento.

\footnotetext{
${ }^{1}$ Mestranda em Ensino de Língua e Literatura na Universidade Federal do Tocantins (UFT) - Campus de Araguaína. Professora no Instituto Federal do Maranhão (IFMA) - Campus de Imperatriz. Pesquisa e publica trabalhos que sobre o ensino de língua estrangeira. E-mail para contato: nr.macedo@ hotmail.com.

${ }^{2}$ Doutora em Linguística pela Universidade Federal de Santa Catarina (2011). Professora efetiva do curso de Letras da Universidade Federal do Tocantins (UFT) - Campus de Porto Nacional, e do Programa de PósGraduação em Letras - campus de Araguaína. Pesquisa e publica trabalhos que versam sobre o papel da fonética e fonologia no ensino de língua materna e língua estrangeira. E-mail para contato: carineh@uft.edu.br. 


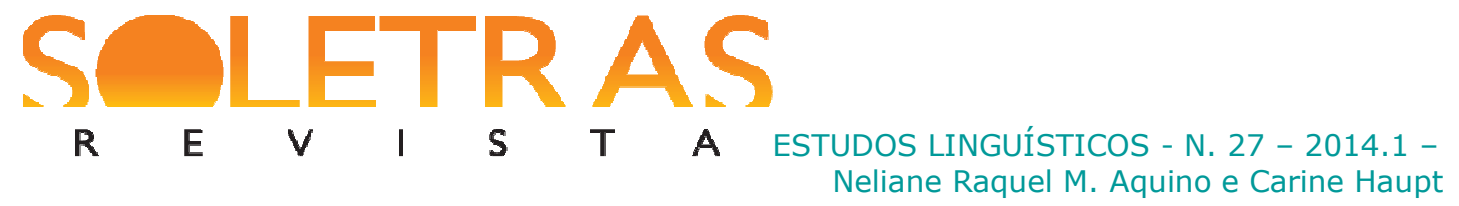

Ao analisar as atividades propostas de um livro didático, por exemplo, é necessário considerar a teoria que os autores desse livro apontam como norteadoras de sua construção. Sendo assim, analisamos, neste artigo, atividades de pronúncia baseadas em aspectos fonético-fonológicos da língua inglesa, pensando-as a partir do interacionismo, abordagem que norteia o livro didático Freeway (2010). A escolha dessa obra se deve ao fato de que, dentro da lista disponibilizada pelo Ministério de Educação para o professor analisar e escolher seu material, o livro Freeway (2010) é o único que traz treinos de pronúncia e identificação de pronúncia de pares mínimos e sentenças mínimas ${ }^{3}$.

Tal característica nos motivou a problematizar essas atividades e seus usos em sala de aula. Tendo em vista que o livro, como afirmado pelos próprios autores, segue uma tendência interacionista da qual se depreende a abordagem comunicativa, propõe-se, primeiramente, uma revisão desses modelos teóricos. Logo depois, falamos brevemente sobre o ensino da pronúncia e, por fim, apreciamos as atividades do livro didático e sua coerência e/ou incoerência com aqueles modelos. Haverá coerência com a abordagem comunicativa quando o foco não for a pronúncia em si, mas a capacidade de comunicar. Autores como Alves e Barreto (2012) demonstram que atividades pronúncia nessa abordagem trazem interação entre os participantes da aula e o exercício oral que possam auxiliar no entendimento da diferença entre os sons da língua materna e da língua-alvo, por exemplo. Se as atividades não tiverem o foco voltado para a interação em sala de aula, haverá incoerência.

\section{O interacionismo e a abordagem comunicativa}

A corrente interacionista tem como um dos principais representantes Vygotsky (1991), o qual é nomeado por alguns estudiosos - em Santos (2011) e em Morato (2009) - como construtivista. Esse construtivismo de Vygotsky (1991) resultou em ideais voltados para o desenvolvimento da linguagem relacionado a fatores externos. Por isso, Morato (2009, p. 311) ressalta que "inicialmente, o interacionismo em Linguística significou uma reação das posições teóricas externalistas contra o psicologismo que impregnava a ciência da linguagem nos meados do século XX".

Vygotsky (1991) defende que a fala e outras representações mentais terão o mesmo desenvolvimento na criança. Seu diferencial está em estabelecer que a fala tem função social,

\footnotetext{
${ }^{3}$ O trabalho é a parte de estudo da dissertação da mestranda. Ressaltamos que aqui não se fez diferença conceitual entre os termos: língua estrangeira, L2 e língua-alvo por não ser esse o objetivo presente.

SOLETRAS, N. 27 (jan.-jun. 2014)

ISSN: 2316-8838

DOI: $10.12957 /$ soletras.2014.7621
} 


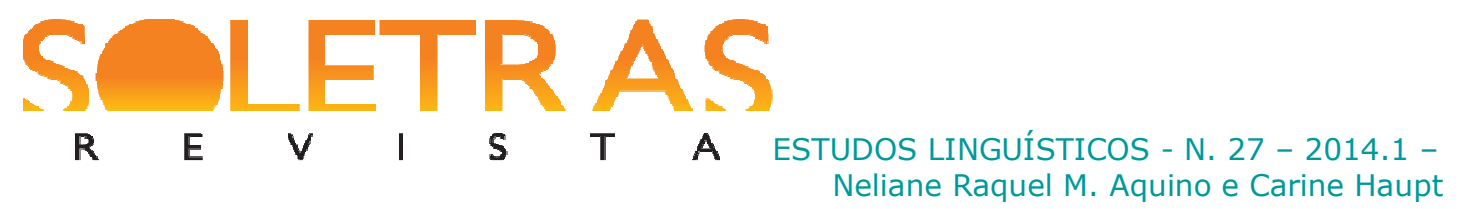

por isso, o interlocutor será relevante para a aquisição da linguagem da criança. Por isso, para a criança, o adulto "[...] cria a intenção comunicativa, como o facilitador do processo de aquisição" (SANTOS, 2011, p. 223).

[...] o autor propõe quatro estágios no desenvolvimento das operações mentais (aí incluídas as operações responsáveis também pelo desenvolvimento da fala): natural ou primitivo (que corresponde à fala préintelectual e ao pensamento pré-verbal); psicologia ingênua (a criança experimenta as propriedades físicas tanto de seu corpo quanto dos objetos, e aplica essas experiências ao uso de instrumentos - inteligência prática); signos exteriores (as operações externas são usadas para auxiliar as operações internas: nesse estágio ocorre a fala egocêntrica); e crescimento interior (em que as operações externas se interiorizam) (SANTOS, 2011, p. 223-224).

Vygostky (1991) segue uma visão construtivista assim como Piaget, mas argumenta que o desenvolvimento da linguagem e também do pensamento da criança têm origens sociais, ou seja, a linguagem é externa e somente com o passar do tempo é que há um processo de interiorização de representação mental do que antes era externalizado. Ainda, o autor reconhece que fala e pensamento prático devem ser estudados sob o mesmo enfoque e, por isso, a fala é posta como viabilização da atividade simbólica que tem como função organizar o pensamento. Assim é que a criança pode administrar o ambiente e o seu comportamento por meio da fala (SCARPA, 2006).

O interacionismo que se desenvolveu a partir dessa concepção toma como uma de suas principais características a interação dita social, isto é, traz para o bojo dos estudos linguísticos a troca comunicativa entre locutor e interlocutor como pré-requisito para o desenvolvimento linguístico. Dessa maneira, podemos afirmar que o interacionismo é uma visão que parte do social para o individual para que se possa explicar o desenvolvimento da linguagem, em particular da fala, como instrumento de comunicação, fator social.

A visão interacionista recebeu várias ramificações, ou nomenclaturas, de acordo com alguma característica que se destacasse; todas partem, entretanto, dessa mesma ideia de inclusão do aspecto social ao desenvolvimento da linguagem. Dentre essas ramificações, citamos o sociointeracionismo, que tem como representantes o próprio Vygotsky (1991), assim considerado devido à importância que adquire o aspecto sócio-histórico na aquisição, e Bahktin (2006), que percebe a língua como produto de atividades sociais. Essa perspectiva é parte da visão interacionista e toma a linguagem como o espaço em que a criança se constrói enquanto sujeito, portanto a linguagem é uma atividade constitutiva do próprio conhecimento de mundo da criança no qual ela apreende o conhecimento de forma segmentada e 


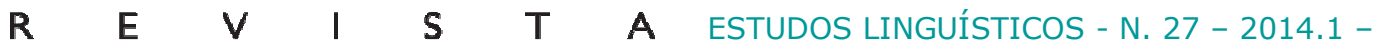 \\ Neliane Raquel M. Aquino e Carine Haupt}

incorporada. Assim é que a linguagem e conhecimento do mundo da criança estão intimamente relacionados, os dois passam pela mediação do outro, do interlocutor (SCARPA, 2006; SCHNEIDER, 2013).

Tendo em vista esse modelo de estudo do desenvolvimento da linguagem, é possível notar o papel que a fala terá nesse contexto. A fala não é simplesmente acúmulo proveniente anteriormente de um locutor. A fala é, pois, crucial na experiência que se tem com o mundo e ajuda a organizar essa experiência. Portanto, há relação direta com a função comunicativa da linguagem. Falar é conhecer a sociedade, o mundo, e possibilitar ser conhecido nesse mundo.

Dentro da perspectiva interacionista aparece uma abordagem que hoje é muito popular: a abordagem comunicativa. No Brasil, ela é muito explorada por Almeida Filho e tem como característica principal o aluno que aprende de forma subconsciente, de acordo com situações simuladas, de interação real, e é essa interação determinante no resultado da aprendizagem do estudante.

Também segue essa linha de estudo Widdowson (2005), o qual ficou bem conhecido pela obra $O$ ensino de línguas para a comunicação e, por meio dela, neste país, várias pesquisas sobre competência/abordagem comunicativa foram desenvolvidas. Nesse texto, o autor demonstra ao leitor a importância do contexto de uso para o ensino de línguas, haja vista que, como menciona, ensinar línguas não é simplesmente ensinar habilidades: ler, falar, ouvir, escrever. Ensinar outra língua compreende possibilitar ao aluno o uso correto dessas habilidades de acordo com o contexto em que se insere. Cremos que seja necessário definir aqui o termo comunicação para essa visão de ensino e aprendizagem:

Concebemos hoje comunicação (sempre de forma incompleta e conscientemente provisória) mais como uma forma de interação social propositada onde se dão demonstrações de conhecimento e troca de informações. A aprendizagem de uma nova língua (L) desse ângulo precisaria se dar numa matriz comunicativa de interação social. Codificar e decodificar informações como num jogo de espelho seria por demais redutivo e insuficiente (ALMEIDA FILHO, 2005, p. 8).

Nesse ambiente é que Almeida Filho (ALMEIDA FILHO, 2005, p. 8) ressalta a interação de sujeitos enquanto histórico-culturalmente situados na tentativa constante de compreender o outro ou o mundo. Portanto, a comunicação verbal toma o conhecimento prévio como fator importante sem dispensar as regras gramaticais, mas sem torná-las o centro do processo, fazendo da percepção da situação de uso e do conhecimento cultural disponível fatores determinantes na aprendizagem. 


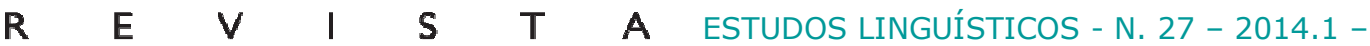 \\ Neliane Raquel M. Aquino e Carine Haupt}

A abordagem comunicativa e a visão interacional dos estudos da linguagem vêm ganhando muitos adeptos ao longo dos anos. A visão interacionista pode ser utilizada como categoria de análise do uso da língua. A abordagem comunicativa é relacionada por vezes aos métodos de sala de aula para apreciação de objetivos diversos sobre por que aprender uma língua estrangeira. Todavia, é necessário que algumas reflexões sejam feitas pelo pesquisador ou pelo professor para que não caiamos num falso interacionismo.

Nesse sentido, Morato (2009) traz interessantes problemáticas a respeito do modelo interacionista. Por exemplo, é necessário estabelecer a diferença entre interação e comunicação. Até que ponto a comunicação que utilizamos na nossa análise é interação? Ainda, utilizamos, como foco de análise, a interação verbal, mas nem sempre é possível separá-la das outras formas de interação. A delimitação do objeto, portanto, se torna algo complexo.

Morato também faz uma reflexão que reproduzimos agora, sobre o termo interação, para que saibamos o terreno onde estamos pisando: é necessário refletir, primeiro, sobre o termo “[...] (inter) - à ideia de influência recíproca; em segundo lugar, ele nos convida a pensar em algo compartilhado de forma reflexiva (isto é, ação)" (MORATO, 2012, p. 315). (Grifos da autora).

Consideramos, por conseguinte, que a análise interacionista e a abordagem comunicativa possibilitam uma visão diferenciada sobre a linguagem enquanto objeto de análise. Elas priorizam o contexto em que está sendo estudada, tendo em vista suas circunstâncias particulares e o fazer comunicativo dos sujeitos do ambiente. Em se tratando de ensino de língua estrangeira, essa visão assegura ao professor um olhar sobre os alunos a partir de seus objetivos de estudo de línguas e uma visão reflexiva sobre o livro didático utilizado em sala de aula.

O ensino da pronúncia numa abordagem comunicativa constitui-se, ainda hoje, de um grande desafio. Um dos fatores que dificulta a inclusão do ensino da pronúncia nessa abordagem reside no fato de que "para os alunos em fase inicial de aprendizagem, uma prática mais comunicativa, que troque informação autêntica e relevante, mostra-se mais difícil" (BARRETO; ALVES, 2009, p. 231-232). No entanto, mesmo ante as dificuldades, o ensino da pronúncia deve fazer parte do processo de aprendizagem de uma língua estrangeira. Nesse sentido, fazemos, a seguir, algumas considerações sobre o papel do ensino da pronúncia. 


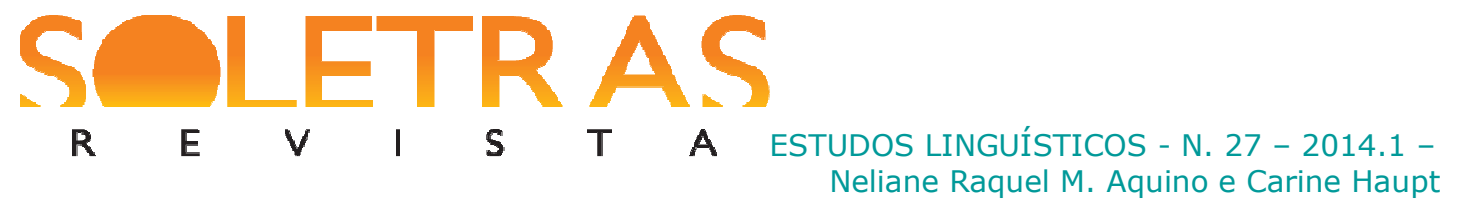

\section{O ensino de pronúncia}

Antes de refletir sobre o livro didático e o ensino, conceituamos pronúncia, lembrando que não se deve confundi-la com fluência. Nas palavras de Neto (2006), pronúncia envolve “os aspectos exclusivamente ligados à percepção e à produção de sons" da língua estrangeira, pois fluência é um termo mais abrangente e considera outros fatores como adequação lexical ao contexto.

Muitos livros didáticos estão sendo organizados para trabalhar todas as habilidades da língua que está sendo adquirida. No caso do ensino de língua estrangeira (LE), essa não era uma grande preocupação há um tempo, visto que a sua aprendizagem estava condicionada à escrita. Agora, há uma ênfase cada vez maior no papel da LE para o aluno e em como a aprendizagem da pronúncia pode auxiliar no desenvolvimento da linguagem.

Como já mencionado, o livro escolhido para análise é o Freeway (2010). Tal escolha parte do fato do tratamento particular dado ao aspecto da pronúncia em sala de aula. É oportuno, para uma boa aprendizagem de LE, que o aluno seja capaz de diferenciar os sons os quais, como alguns trabalhados no livro, muitas vezes não existem na língua materna, no nosso caso, na língua portuguesa. Em vista disso, Cristófaro-Silva (2006, p. 9) argumenta que "a familiaridade com os padrões sonoros da língua estrangeira oferecerá ao aprendiz a oportunidade de ter um desempenho significativamente mais acurado na língua que está sendo aprendida. Uma comunicação eficaz procede".

Como assevera Souza (2009, p. 34), “o objetivo de se ensinar pronúncia, atualmente, é desenvolver nos alunos habilidade de pronúncia suficiente para uma comunicação efetiva com falantes nativos" e, acrescentamos ainda, para que ele ou ela seja capaz de entender e de se comunicar dentro da necessidade de sua formação globalizada atual mesmo que não tenha contato direto com um nativo. Dessa maneira, possibilitar certo nível de conscientização dos sons da língua-alvo é parte integrante do ensino de outra língua. Schmidt (1990, apud ALVES, 2012) propõe dois níveis de consciência na instrução explícita - notar e entender - os quais demonstram a familiaridade com a língua-alvo. $\mathrm{O}$ aluno pode notar um registro de forma consciente de algum aspecto da língua, como ocorre no livro com as descrições de pares mínimos - "pares de palavras que se diferenciam por um único fonema" (ALVES, BARRETO, 2012, p. 195) - mas somente o entende quando ele consegue sistematizar essas diferenças. 


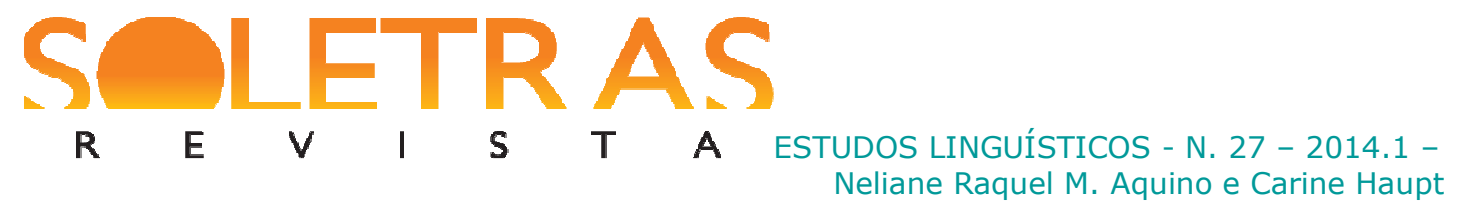

Esses processos cognitivos fazem parte do aprender uma língua estrangeira e não podem ser esquecidos, uma vez que se corre o risco de a língua-alvo ser comparada a língua materna e não haver a necessária diferenciação de sons, principalmente daqueles que não existem na língua materna. Para Ellis (2005, p. 14), o conhecimento explícito pode auxiliar no desenvolvimento da linguagem, o que facilita o desenvolvimento do conhecimento implícito (tradução nossa). A pronúncia é um aspecto formal da língua e, portanto, deve ser trabalhada em sala de aula como qualquer outro aspecto formal.

\section{Análise do livro didático}

O livro didático Freeway (2010) é composto de três volumes, um para cada ano do Ensino Médio. Entretanto, só o livro 1 (primeira série do Ensino Médio, 2010) traz atividades de pronúncia baseados em princípios fonético-fonológicos. Em primeira observação, supomos que isto acontecesse porque os autores percebem os alunos de primeira série do Ensino Médio como iniciantes, e os demais, já tendo tido o contato necessário com a fonética da língua, não necessitariam de um estudo mais detalhado. Porém, cremos que o tempo de contato com os símbolos e as pronúncias dependerá muito mais do aluno e dos objetivos da aula. Sendo assim, o livro introduz elementos que o professor pode utilizar posteriormente nas aulas, de acordo com as dificuldades dos alunos.

As atividades do livro são referentes ao contraste das pronúncias dos fonemas vocálicos

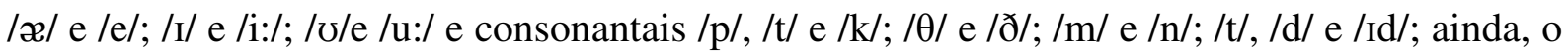
contraste entre /l/, /t/, /d/ e /b/ (silent consonants) e, por fim, palavras com mais de uma pronúncia em contextos frasais diferentes, a exemplo da preposição of /ov/ que assume as pronúncias /əv/ antes de vogais e /ə/ antes de consoantes em posição átona. Todos os sons e frases podem ser ouvidos no CD que acompanha o livro. Apesar de poucas atividades, o livro, de uma forma geral, apresenta questões de pronúncia do inglês as quais são dadas como muito difíceis para os falantes do português, como é o caso do chamado "th". Permitem, então, que o aluno perceba quais são suas dificuldades na aprendizagem da língua estrangeira e porque muitas palavras parecem tão "diferentes" quando pronunciadas.

Esse nível de consciência da pronúncia da língua pode facilitar não só o trabalho do professor, como também, e principalmente, a aquisição do conhecimento pelo aluno e, por que não, a motivação do aluno. Apresentar os símbolos fonético-fonológicos, por exemplo, 


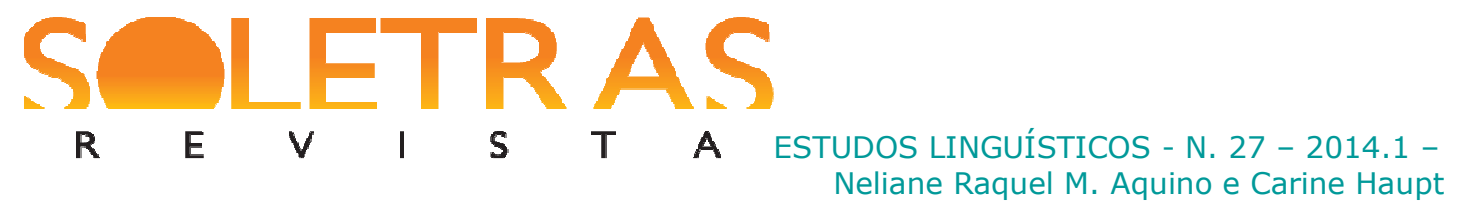

pode dar uma maior independência a consultas a dicionários, os quais, por muitas vezes, vêm com a descrição da pronúncia, que se inviabiliza pela não familiaridade com os símbolos. Assim, o aluno, uma vez reconhecidos os símbolos de seu dicionário, fica mais independente no estudo da pronúncia, não se limitando ao que ouve do professor.

É interessante ressaltar que o livro traz uma bibliografia comentada que visa esclarecer a que se propõe o material pela forma como foi construído. Nessa bibliografia, os autores explanam que:

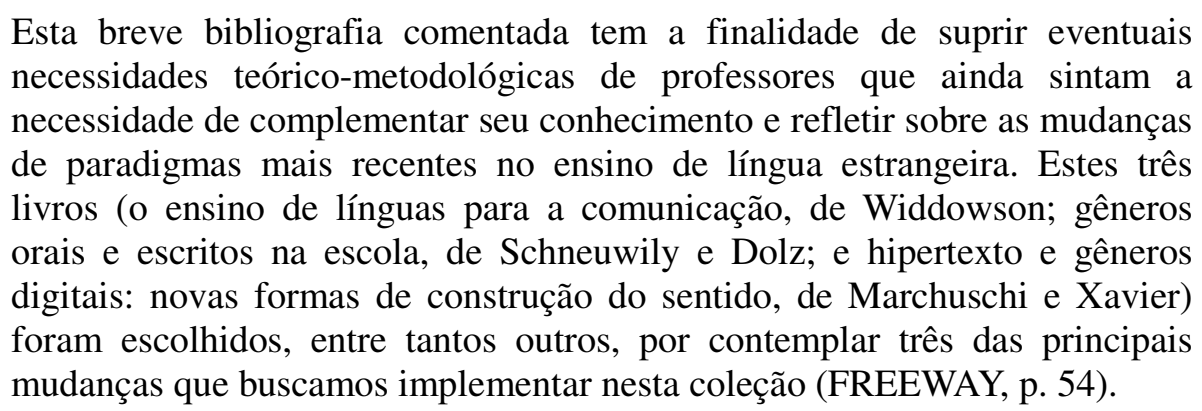

Podemos perceber, à vista disso, que o livro tenta inserir-se numa visão interacionista de aprendizagem de LE. Ao implementar as ideias comunicativas de Widdowson (2005), os autores apontam para a necessidade de desenvolvimento de todas as habilidades da língua e, assim, possibilitam atividades que contemplem a fala no conjunto da aula. Essa fala, no entanto, tem, para Widdowson (2005), um foco comunicativo. Na verdade, toda a aprendizagem para o autor deve ser voltada para o sentido para a produção da atividade comunicativa. Constatamos, porém, que o livro não está centralizado nessa perspectiva, mas passeia por ela em alguns momentos. O livro abarca, de maneira geral, tanto aspectos gramaticais da língua quanto aspectos comunicativos.

Sobre as páginas de atividade de pronúncia - Pronunciation Practice -, os autores do livro didático afirmam que,

As atividades propostas abordam alguns dos fonemas mais difíceis para a
pronúncia dos alunos brasileiros. A forma como elas estão dispostas permite
que os alunos entrem em contato primeiramente com os sons que costumam
ser confundidos, e na sequência, façam uma atividade para exercitar a
distinção entre eles (item Guia do livro didático, p. 6).

Em vista de melhor observar a disposição das atividades, apresentamos algumas transcrições da unidade de Pronunciation Practice (p. 150-153):

Vowels

1 Listen to the following minimal pairs and repeat.

\begin{tabular}{|l|l|l|l|}
\hline$/ 2 /$ & $/ \mathrm{e} / \mathrm{I} /$ & $/ \mathrm{i}: /$ \\
\hline
\end{tabular}




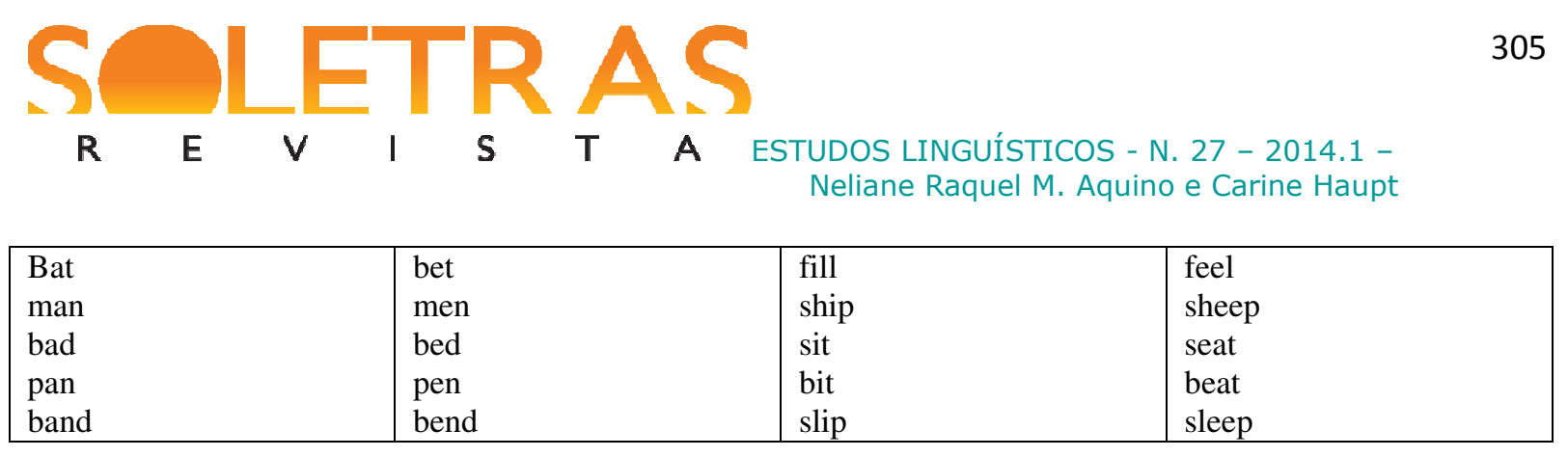

Nessa atividade, o foco está no treino de pares mínimos de alguns fonemas vocálicos. O treino ajuda o aluno a diferenciar quando ocorrem esses sons que são parecidos, mas não iguais, e que geram oposição, diferença de significado. Alguns deles são difíceis para nós falantes do português brasileiro, por não existirem no nosso conjunto fonológico. $\mathrm{Na}$ atividade, treina-se o /æ/ e o /i:/, fonemas que são típicos do inglês, mas que, por não termos familiaridade, não os percebemos. Essas propostas de atividades de pronúncia de sons específicos que não existem no português brasileiro podem ser vistas de maneira positiva, já que muitos alunos sentem dificuldade na compreensão da língua alvo. Com essas atividades, o aluno pode tanto trabalhar a pronúncia para comunicar-se melhor quanto ouvir melhor e entender o que está sendo dito por outro falante, até mesmo por um nativo.

Outras atividades são igualmente relevantes ao entendimento de processos fonéticofonológicos do inglês. Por exemplo, há atividades que treinam a pronúncia da coda de alguns verbos como encontramos na página 152 :

12. Listen to the three different ways in which the $-e d$ suffix is pronounced and repeat.

th passed, laughed Id/ opened, lived II/ counted, sounded

Essa atividade mostra ao aluno o que ocorre com o sufixo ed que recebe diferentes pronúncias: em algumas situações, como na primeira, a pronúncia é diferente da escrita, passando o sufixo a ser pronunciado como /t/, em /læft/; e em outros, como ocorre na segunda, há uma vogal presente no sufixo que não é pronunciada, como em /livd/ - live êd.

Por último, destacamos também a atividade que traz as chamadas silent consonants: /1/ /t/ - /d/ - /b/. Neste último exemplo de atividade, os autores propõem um treino de pronúncia com palavras que sofrem apagamento, ou seja, com consoantes que, embora estejam presentes na escrita, não são pronunciadas (p. 152).

15. Listen to the pronunciation of the following words and underline those that contain a silent $/ \mathrm{l} / \mathrm{-} / \mathrm{t} / \mathrm{-} / \mathrm{d} / \mathrm{-} / \mathrm{b} /$.

\begin{tabular}{|c|c|c|c|c|c|c|}
\hline world & often & faster & almond & bomb & would & Wednesday \\
\hline chalk & cold & palm & $\underline{\mathrm{comb}}$ & banana & whistle & tomb Bob \\
\hline
\end{tabular}




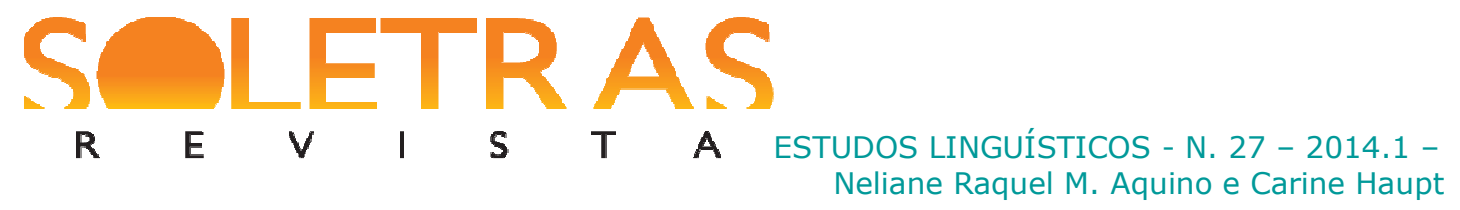

Uma vez que não tem foco no significado, no sentido, e, portanto, não estabelecem uma situação comunicacional, não podemos ver essas atividades como sendo de uma abordagem comunicativa. Como apontam Barreto e Alves (2012, p. 235), essas atividades têm característica de "[...] listen and repeat, em que o foco é o aspecto fonético-fonológico a ser ensinado, independente do conteúdo comunicativo em que tal aspecto possa ser inserido". De acordo com Barreto e Alves (p. 233), "[...] é preciso oportunizar a produção da língua-alvo em situações de interação na L2 com o professor e com os colegas". Já que o livro não oportuniza essa interação, há que se observar que a proposta de Pronunciation Practice está distante do que propõe a teoria interacionista.

Em se tratando da abordagem comunicativa, a pronúncia seria praticada com foco no sentido, ou seja, as atividades girariam em torno "do que se quer dizer" e não "do como dizer". Assim, alunos podem interagir com o professor e entre si, buscando, por exemplo, como se referir a um homem ou a um conjunto de homens executando uma ação (o livro apresenta a diferença na pronúncia entre man - singular - e men - plural).

$\mathrm{Na}$ perspectiva que propõe Widdowson (2005), percebemos que os exercícios de pronúncia sugeridos no referido livro didático são como testes de pronúncias descontextualizados, não permitindo a comunicação entre interlocutores. Destarte, classificálos-íamos como atividades de speaking - uma espécie de repetição correta de uma frase - ou até mesmo saying - resposta a uma pergunta sem conseguir interagir verdadeiramente. Por isso,

[...] manifesta-se a capacidade linguística desses usuários, mas não necessariamente sua habilidade de comunicação. [...] Esses rápidos exemplos demonstram que a relação entre habilidades que possibilitam a comunicação oral é mais complexa do que a simples capacidade de produzir e decodificar frases isoladas (DONNINI; PLATERO; WEIGEL, 2010, p. $67)$.

Por outro lado, a percepção focalizada dos sons durante a aula é um exercício que permite desenvolver outra característica da língua, a melhora no desempenho. A repetição de sons torna a articulação mais automática, possibilitando maior precisão na produção fonética. Como todos os excertos trazem conhecimentos particulares da pronúncia do inglês que são consideradas difíceis de perceber para quem fala português devido à dinâmica própria da língua-alvo, essas atividades podem tornar a comunicação mais eficiente. Para tanto, o professor não pode perder de vista que essas atividades servem para melhorar a expressão do conteúdo comunicativo, ou seja, são mais do que um simples conteúdo (BARRETO; ALVES, 


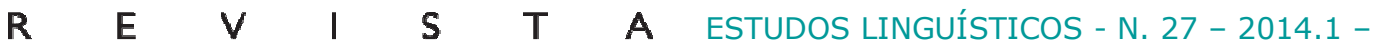 \\ Neliane Raquel M. Aquino e Carine Haupt}

2009). Na medida em que o aluno vai desenvolvendo sua proficiência na língua, deve-se partir para uma prática mais comunicativa e significativa. Nesse sentido, essas atividades são apenas um início no desenvolvimento de uma comunicação eficaz e mais acurada na língua estrangeira.

Seguindo a linha de reflexão de Donnini, Platero e Weigel (2010), é necessário nos perguntarmos, enquanto professores, sobre que habilidades ensinamos aos alunos e como elas se relacionam, o porquê de textos orais em sala e como trabalhá-los. Um exercício como o proposto das páginas de pronúncia, por exemplo, poderia auxiliar o aluno a "lidar com fatores afetivos que podem interferir negativamente na produção oral e colaboram para o desenvolvimento da precisão e da fluência na comunicação" (DONNINI; PLATERO; WEIGEL, p. 67), pois exigem ensaio e monitoração. Além disso, dependendo de sua aplicação, esses exercícios de pronúncia podem gerar interação entre professor e alunos.

Assim sendo, essas atividades são necessárias para a fluidez e constituem uma contribuição para que se consiga uma aprendizagem sólida, uma vez que a competência comunicativa não é a única habilidade necessária a ser desenvolvida na aprendizagem de língua. Acreditamos, pois, que atividades como as do livro, reconhecidamente não direcionadas à abordagem comunicativa, são também importantes ao contexto de sala de aula. Essas atividades representam um ganho ao professor e ao aluno, uma vez que diversificam o trabalho de sala de aula e dão a oportunidade de o aluno "refinar" a pronúncia. Esse refinamento permite o melhor entendimento da língua em questão e reconhecimento das palavras em outros contextos que não o de sala de aula. Portanto, o exercício da pronúncia auxilia na capacidade ouvir, e, até mesmo, de ler.

A mediação entre os tipos de atividades se torna essencial a ser pensada pelo professor de língua, porque todas têm seu papel de importância. Assim nem todo momento de aula precisa ser comunicativo, pois para comunicar há muito mais que se pensar do que apenas em interagir verbalmente em sala. O pensar sobre a língua também faz parte de desenvolver o conhecimento linguístico.

\section{Considerações Finais}

Como consideração final, observamos que unidade denominada Pronunciation Practice é muito mais um treino para o ouvido do que realmente atividade de pronúncia. Os comandos 


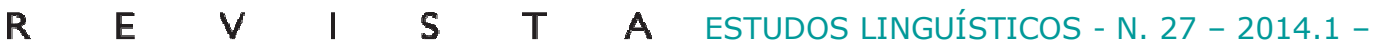 \\ Neliane Raquel M. Aquino e Carine Haupt}

estão direcionados a ouvir e marcar ou a ouvir, entender e diferenciar. A prática da fala pelo aluno acontece em momentos de repetição, apenas. A prática que esperávamos encontrar de exercícios que exigissem mais a capacidade comunicativa do aluno não aconteceu. Cabe, então, a iniciativa do professor. Portanto, há que se pensar que ainda há uma distância entre o que propõe os autores do livro com vista à abordagem comunicativa e o que realmente acontece no uso dessas atividades. Nas palavras de Barreto e Alves (2012, p. 234):

[...] ainda que se ressalte, nos dias atuais, a importância de um ensino de pronúncia em que a explicitação dos sons da língua se dê de modo integrado a um objetivo e a um contexto significativo, parece que, em termos práticos, a realidade é um tanto diferente [...], parece que, no que diz respeito ao ensino de pronúncia, as técnicas e práticas se mostram bastante atrasadas, se comparadas ao ensino dos outros aspectos formais da L2.

Consideramos que é possível a prática de atividades de pronúncia na abordagem comunicativa, como querem os autores, em que a pronúncia está presente em contextos em que o foco seja a comunicação, e não o treino e a melhora do desempenho. Assim, na montagem de um diálogo, por exemplo, entre dois alunos, um observará a pronúncia do outro a fim de entender o seu interlocutor e fará as intervenções que julgar necessárias. Mas isso não quer dizer que as atividades expostas sejam ruins, pelo contrário, devemos lembrar que nem toda aula precisa ser baseada no modelo comunicativo, pois, para comunicar, é necessário também que a pronúncia seja inteligível e momentos de análise explícita da pronúncia podem ajudar muito. Devemos também lembrar que pronunciar outra língua é tarefa difícil principalmente quando esta possui “ortografia opaca, ou seja, em que há diferença marcante entre pronúncia e escrita” (ALVES, BARRETO, 2012), como é o caso do inglês.

As teorias de ensino de língua em muito contribuem à prática de sala de aula. É necessário, todavia, que façamos as reflexões necessárias sobre essa contribuição. Todas elas recebem críticas e acreditamos que a maior questão não é até que ponto a teoria está correta, mas como elas podem estar aliadas à prática. De cada uma delas podemos depreender aspectos relevantes ao processo de ensinar e aprender.

Destacamos também que alguns autores defensores da própria abordagem comunicativa já fizeram seus questionamentos a ela, como Widdowson (2005) e Almeida Filho (2005), com certo grau de ceticismo sobre o que muitos, no advento da abordagem, chamaram de "revolução do ensino de línguas". Isso demonstra a inquietação e a necessidade de pensar a prática todos os dias e de avaliar como essas teorias podem responder junto a ela. Essa 


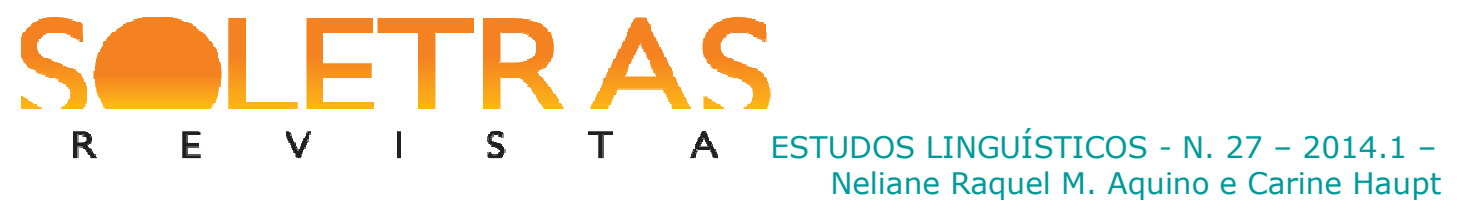

necessidade não deveria ser particular do pesquisador, mas também do professor, já que esses dois não deveriam se separar.

Não há abordagem, em nossa opinião, "correta" ou "errada", a questão a ser discutida é o contexto específico em que a abordagem está sendo inserida e, assim, a pergunta a ser respondida é: a abordagem a que se propõe o ensino está gerando, de fato, aprendizagem, ou seja, está correspondendo com o objetivo proposto? Nessa perspectiva é que afirmamos que o professor pode determinar a diferença entre uma atividade dita comunicativa com foco na interação e uma atividade dita "tradicional". Relembramos, porém, que mesmo que o objetivo seja a comunicação, há outros fatores além do falar interagindo que devem ser pensados para a sala de aula. Assim, atividades de monitoramento e repetição também têm sua parcela de contribuição à aprendizagem do aluno.

\section{Referências bibliográficas:}

ALMEIDA FILHO, J.C.P. Dimensões Comunicativas no Ensino de Linguas. 5. ed. Campinas, SP: Pontes, 2005.

ALVES, U. K. A explicitação dos aspectos fonético-fonológicos da L2: teoria e pesquisa na sala de aula. In: LAMPRECHT, R. R. et al. Consciência dos sons da língua: subsídios teóricos e práticos para alfabetizadores, fonoaudiólogos e professores de língua inglesa. 2. ed. Porto Alegre: EdiPUCRS, 2012, p. 211-230.

ALVES, U. K.; BARRETO, F. M. O processamento e a produção dos aspectos fonéticofonológicos da L2. In: LAMPRECHT, R. R. et al. Consciência dos sons da língua: subsídios teóricos e práticos para alfabetizadores, fonoaudiólogos e professores de língua inglesa. 2.ed. Porto Alegre: EdiPUCRS, 2012, p. 193- 209.

BAKHTIN, M. Marxismo e filosofia da linguagem. 12. ed. São Paulo: HUCITEC, 2006.

BARRETO, F. M.; ALVES, U. K. Como inserir o ensino comunicativo de pronúncia na sala de aula de L2. In: LAMPRECHT, R. R. et al. Consciência dos sons da língua: subsídios teóricos e práticos para alfabetizadores, fonoaudiólogos e professores de língua inglesa. 2.ed. Porto Alegre: EdiPUCRS, 2012, p. 231-258.

CRISTÓFARO-SILVA, T. O Ensino de pronúncia na aula de Língua Estrangeira. http://www.projetoaspa.org/cristofaro/publicacao/pdf/ensinopronuncia-2006-ms.pdf. Acesso em 24 de julho de 2013. p.1-10.

DONNINI, L.; PLATERO, L.; WEIGEL, A. Ensino de língua inglesa. Coleção Ideias em Ação. São Paulo: Cengace Learning, 2010. 


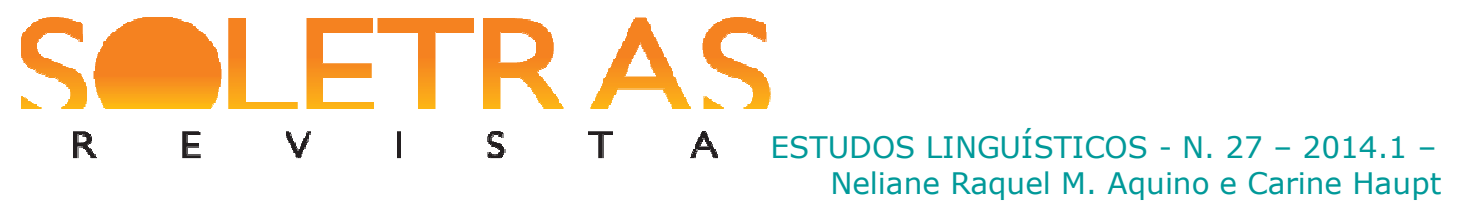

ELLIS, R. Principles of Instructed Language Learning. Ilhas Virgens Britânicas: Asian EFL Journal, v. 7, n. 3, p. 9-24, set. 2005.

MORATO, E. M. O interacionismo no campo linguístico. In: MUSSALIM, F.; BENTES, A. C. (Orgs.). Introdução à Linguística 3: fundamentos epistemológicos. 4. ed. São Paulo: Cortez, 2009, p. 311-351.

NETO, T. N. Uma concepção alternativa de educação formal aplicada ao ensino de pronúncia em inglês. 2006. 302f. Tese (Doutorado em Estudos Linguísticos) - Universidade Federal de Minas Gerais, Belo Horizonte, 2006.

PRAHBU, N.S. The dynamics of the language lesson. Tesol Quartely, v. 26, n. 2, 1992. p. 7996.

SANTOS, R. A aquisição da linguagem. In: FIORIN, J. L. (Org.). Introdução à Linguística I: objetos teóricos. São Paulo: Contexto, 2011, p. 211-227.

SCARPA, Ester Miriam. Aquisição da linguagem. In: MUSSALIM, F.; BENTES, A. C. (orgs). Introdução à linguística 2: domínios e fronteiras. 5. ed. São Paulo: Cortez, 2006, p. 203-232.

SCHNEIDER, Castilho Francisco. Aquisição da linguagem oral e escrita. Disponível em: http://www.ulbra.br/letras/files/aquisicao-da-linguagem-oral-e-escrita.pdf. Acesso em 19 de julho de 2013.

SOUZA, Marcela O. P. de. A Fonética como importante componente comunicativo para o ensino de língua estrangeira. Revista Prolíngua, UFPB, v. 2 , n. 1, p. 33-43, jan.-jun. 2009.

TEODOROV, V. (Ed). Freeway. São Paulo: Richmond Educação, v. 1, 2010.

VYGOTSKY, L. S. A formação social da mente. 4. ed. São Paulo: Martins Fontes, 1991.

WIDDOWSON, H. G. O ensino de línguas para a comunicação. 2. ed. Campinas, SP: Pontes, 2005.

\section{The textbook in foreign language teaching: activities of pronunciation}

Abstract: The paper "the textbook in teaching of foreign language: pronunciation activities" was thought to helps the teacher with the classroom practices. Theories of language acquisition permit us to reflect on the classroom practice we have nowadays. Thinking about this relationship, it is also necessary that the available material to the teachers to be analyzed. Thus, it is proposed in this article, from a brief theoretical review of interaction hypothesis and communicative approach, a reflection on proposed activities in a textbook concerning in relation to the specific pronunciation activities in classroom. We take as corpus this analysis 


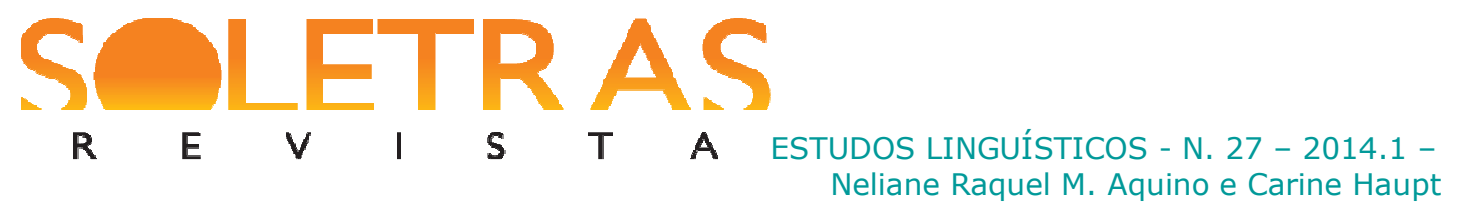

the textbook Freeway (2010) - English as a foreign language (EFL) - because it is the chosen one by the MEC, and acquired by public schools which has activities that exercise pronunciation based on phonetic and phonological knowledge. The relevance of discussing this question is the importance of the student realizes the differences of the sound systems of the native language and the target language in this acquisition process. We observe that the textbook activities are relevant, but they are not consistent with a communicative approach, as suggested by the authors. However, there is still some distance between what is proposed by the author and what is practiced, these pronunciation activities improve the performance and can assist, consequently, in an effective communication.

Keywords: English Language. Textbook. Pronunciation. Interaction. Communicative Approach.

Recebido em: 03 de outubro de 2013.

Aprovado em: 10 de dezembro de 2013. 